\title{
Validation of an HIV-related stigma scale among health care providers in a resource-poor Ethiopian setting
}

This article was published in the following Dove Press journal:

Journal of Multidisciplinary Healthcare

27 March 2012

Number of times this article has been viewed

\author{
Garumma Tolu Feyissa' \\ Lakew Abebe' \\ Eshetu Girma' \\ Mirkuzie Woldie ${ }^{2}$ \\ 'Department of Health Education \\ and Behavioral Sciences, ${ }^{2}$ Department \\ of Health Services Management, \\ Jimma University, Jimma, Ethiopia
}

Background: Stigma and discrimination (SAD) against people living with human immunodeficiency virus (HIV) are barriers affecting effective responses to HIV. Understanding the causes and extent of SAD requires the use of a psychometrically reliable and valid scale. The objective of this study was to validate an HIV-related stigma scale among health care providers in a resource-poor setting.

Methods: A cross-sectional validation study was conducted in 18 health care institutions in southwest Ethiopia, from March 14, 2011 to April 14, 2011. A total of 255 health care providers responded to questionnaires asking about sociodemographic characteristics, HIV knowledge, perceived institutional support (PIS) and HIV-related SAD. Exploratory factor analysis (EFA) with principal component extraction and varimax with Kaiser normalization rotation were employed to develop scales for SAD. Eigenvalues greater than 1 were used as a criterion of extraction. Items with item-factor loadings less than 0.4 and items loading onto more than one factor were dropped. The convergent validity of the scales was tested by assessing the association with HIV knowledge, PIS, training on topics related to SAD, educational status, HIV case load, presence of an antiretroviral therapy (ART) service in the health care facility, and perceived religiosity.

Results: Seven factors emerged from the four dimensions of SAD during the EFA. The factor loadings of the items ranged from 0.58 to 0.93 . Cronbach's alphas of the scales ranged from 0.80 to 0.95 . An in-depth knowledge of HIV, perceptions of institutional support, attendance of training on topics related to SAD, degree or higher education levels, high HIV case loads, the availability of ART in the health care facility and claiming oneself as nonreligious were all negatively associated with SAD as measured by the seven newly identified latent factors.

Conclusion: The findings in this study demonstrate that the HIV-related stigma scale is valid and reliable when used in resource-poor settings. Considering the local situation, health care managers and researchers may use this scale to measure and characterize HIV-related SAD among health care providers. Tailoring for local regions may require further development of the tool.

Keywords: stigma, discrimination, health care providers, HIV

\section{Introduction}

Since the beginning of the human immunodeficiency virus (HIV) epidemic, stigma and discrimination (SAD) have been identified as the major obstacles to effective responses to HIV. ${ }^{1}$ HIV-related SAD is a complex social process that influences and reinforces preexisting SAD associated with sexuality, sex, race, and poverty. ${ }^{2} \mathrm{HIV} /$ acquired immunodeficiency syndrome (AIDS)-related SAD occur everywhere, but they may have more serious consequences in health care settings. ${ }^{3}$

Service providers in health care institutions are expected to provide social and psychological support to persons living with HIV (PLHIV) in order to help them
Correspondence: Garumma T Feyissa PO Box 1637 Jimma, Ethiopia

Tel +25 I 91317549 I

Email garummatolu@yahoo.com 
cope with stress and to reduce the stigma directed against PLHIV. However, HIV/AIDS-related SAD has been extensively documented among health care providers. There have been many reports from health care settings of HIV testing without consent, breaches of confidentiality, labeling, gossip, verbal harassment, differential treatment, and even denial of treatment. ${ }^{3-15}$ People who feel stigmatized by health care providers face problems accessing HIV testing and optimal health care services. The fear of stigma impedes prevention efforts, including discussions of safer sex and the prevention of mother-to-child transmission. ${ }^{16-26}$

Reduction of HIV/AIDS-related SAD among health care providers will benefit not only marginalized PLHIV and their associates, but also health care providers themselves. Studies indicate that PLHIV delay accessing health care services because of the fear of SAD. ${ }^{27-30}$ Understanding the prevalence and causes of underlying HIV-related SAD amongst health workers is necessary for the successful development of antistigma strategies and programs. ${ }^{1,29}$ In an effort to quantify HIV/AIDS-related SAD, expert working groups have been trying to develop a core set of global programand community-level indicators. In 2006, the United States Agency for International Development (USAID) Interagency Working Group (IWG) on Stigma and Discrimination Indicators designed specific tools to measure SAD among communities, facilities/providers, and PLHIV. This working group developed tools in four key dimensions: (1) the fear of casual transmission and refusal to come into contact with PLHIV; (2) value and morality-related attitudes: blame, judgment, and shame; (3) enacted stigma (discrimination); and (4) disclosure. ${ }^{1,15}$

The USAID | Health Policy Initiative, Task Order 1, took the lead to develop a health care facility/provider stigma measurement tool. In line with this, the Health Policy Initiative supported three field studies: one in Kenya, ${ }^{14}$ one in the Ukraine, ${ }^{13}$ and an Internet-based study designed to further test indicators and questions regarding HIV-related SAD at the facility/provider level. The Internet-based study recommended that the indicators should be further tested in local settings to assess the impact of language and cultural nuances. The authors of the study acknowledged the possibility that the study was hampered by the small sample size, and that the Internet-based questions would not have been accessible in those areas where Internet services were unavailable, such as rural Ethiopia. ${ }^{30}$

These studies used different scales and even different dimensions of SAD. For example, the Internet-based study has added an 'experienced stigma' dimension. ${ }^{13,14,30}$ The study conducted in the Ukraine concluded that there is a need to further refine the indices, and to tailor the tools to the study context. While efforts are being made to establish standard tools internationally, this process has not yet been finalized. ${ }^{13}$ This study aimed to validate items designed to measure HIV/AIDS-related SAD among health care providers in a resource-poor setting.

\section{Methods and materials Study design}

A cross-sectional quantitative study was conducted in the Limmu Genet Hospital, and in 17 other health centers in the Jimma zone from March 14, 2011 to April 14, 2011.

\section{Study context}

In 2009, there were estimated to be 1.2 million PLHIV in Ethiopia, with an adult HIV prevalence of $2.4 \%$. The HIV/ AIDS epidemic in Ethiopia is generalized, with significant heterogeneity between regional states and population groups. The major mode of HIV transmission is heterosexual; accounting for $87 \%$ of all infections. ${ }^{31-34}$ Ethiopia has laws and regulations that protect PLHIV against discrimination. These include both general nondiscriminatory provisions, and other provisions that specifically mention HIV in relation to such issues as schooling, housing, employment, and health care. Mandatory HIV testing for employment is strictly prohibited under the country's Labor law. ${ }^{35}$ Additionally, the national Civil Service Workplace HIV/AIDS Guideline protects PLHIV from discrimination by employers. ${ }^{36}$ Governmental sectors and nongovernmental organizations have been working hard to support the implementation of these laws and regulations (eg, the Ethiopian Human Rights Commission, Federal Ministry of Labor and Social Affairs, Federal Ministry of Women's Affairs, Ethiopian Women Lawyers Association, Women's Coalition, Women's PLHIV network, and others). The Ethiopian Women Lawyers Association provides free legal services to PLHIV, and there are programs to reduce HIV-related SAD and raise awareness among PLHIV concerning their rights. The promotion and protection of the human rights of PLHIV is explicitly mentioned in the Ethiopian HIV/AIDS policy. ${ }^{32,33}$

\section{Participants}

The Jimma Administrative Zone is found in Oromia Regional State, in southwest Ethiopia. The main town, Jimma, is located $357 \mathrm{~km}$ away from Addis Ababa, the capital city of Ethiopia. In the zone, there are 54 health centers and one district hospital. During the data collection period (from 
March 14, 2011 to April 14, 2011), there were 567 health care providers working in the 54 health centers, and 74 health care providers working in Limmu Genet Hospital. All the health centers were assumed to be the same in relation to the study because their staffing patterns and administration structures were all typical for the Ethiopian context.

The study therefore included all 74 health care providers working in Limmu Genet Hospital, and 190 health care providers working in the 17 randomly selected health centers during the study period. This gave a total of 264 health care providers who could be approached for the study.

\section{Instruments and measures}

Self-administered questionnaires were used to collect the data. The final English version of the questionnaire is presented in Appendix 1. The questionnaires were translated into Amharic (the official language of Ethiopia) and Afaan Oromo (a local language), and then translated back into English to ensure semantic equivalence. The questionnaires were then pretested on the health care providers in the health centers found in Jimma town (not included in the study), making up 5\% of the study population, before the actual data collection began.

The questionnaires contained sociodemographic variables (age, sex, marital status, religion, perceived religiosity, monthly income, educational status, ethnicity, and educational qualification), personal experience (HIV case load, work experience, and previous training on topics related to HIV/ AIDS-related SAD), HIV knowledge, perceived institutional support (PIS) and items to measure HIV/AIDS-related SAD. There were three items used to measure in-depth knowledge of HIV. Basic knowledge of HIV (two items) was assessed by asking participants to identify the bodily fluids which can carry a high enough concentration of HIV to transmit the virus. These items were adapted from previous studies. ${ }^{15,30}$

PIS is both the awareness and understanding of the policies supporting PLHIV, personal protection equipment, and HIV-related protocols. PIS was measured by questions about the availability of personal protective equipment (sterile gloves, sterile needles, rubbing alcohol, disposable containers, and autoclaves), and protocols related to HIV care, the presence and enactment of policies protecting PLHIV against discrimination, and the presence of policies that support health care providers who work with PLHIV. ${ }^{30,37}$ Questions related to the availability of HIV care protocols enquired whether the protocols relating to HIV counseling and testing, confidentiality, informed consent, postexposure prophylaxis, treatment of opportunistic infections, and if universal precautions were readily available or not.
All of the items used to measure SAD were scored using a four-point Likert scale, with higher scores indicating higher SAD. Some items were stated negatively and reverse-coded to reduce the possibility of response-pattern bias. During the pretest, the participants were asked to match each of the items to their corresponding dimensions. Then, substantive validity coefficients (CSV) were calculated for each of the items. The CSV was calculated as the difference between the number of participants assigning an item to its hypothesized construct, and the highest number of assignments of an item to any other construct; that quantity was then divided by the number of responses. A CSV of 0.5 was taken as the cut-off point to drop items that did not correlate with the set of items in their corresponding constructs, to maintain the substantive validity of the questionnaire. ${ }^{38}$ After this, the clarity of the instructions, the wording, whether additional instructions were needed, and cultural acceptability of the questions were pretested.

Exploratory factor analysis (EFA) with principal component extraction and varimax with Kaiser normalization rotation was employed to develop scales for SAD and PIS. Eigenvalues of greater than 1 were used as a criterion for factor extraction. Items with loadings of less than 0.4 and double-loaded items were dropped. ${ }^{15,30}$ Only the items that loaded strongly (greater than 0.40 ) onto their corresponding factors, and the items that loaded more strongly on to their corresponding factor than on any other factor were retained to ensure respective convergent and discriminant validities. The items which did not load as expected on the intended factor were dropped to maintain the face validity of the instrument. $^{39}$

A Cronbach's alpha of 0.70 or greater was accepted as the internal consistency of each scale. Selected items were deleted to significantly increase the Cronbach's alpha of the scale. ${ }^{40,41}$

\section{Data collection procedure}

Data were collected by nine health professionals with a BSc qualification using a pretested questionnaire after 2 days' training to familiarize them with the instruments. Participant names in the questionnaires were replaced by codes, and participants were advised so that they had a record of their own codes to facilitate tracking of the completeness of their respective questionnaires. The completeness of the data was checked on-site, and the codes for incomplete questionnaires were posted for the participants. Incomplete questionnaires were placed in offices assigned for participants to complete their questionnaires. The data collection 
was supervised by two Masters of Public Health students and the principal investigator.

\section{Data processing and analysis}

Data were checked for completeness, and were entered into EPIDATA (version 3.1; EpiData Association, Odense, Denmark). After double-entry verification, the data were exported to SPSS software (version 16.0; SPSS Inc, Chicago, IL) for analysis. The data were explored using descriptive analyses to clean data-entry errors. Factor analysis was then conducted to create scales for SAD and PIS. Assumptions of factor analysis, including sampling adequacy and multicollinearity were checked. Factor scores were created and used in the subsequent analyses. Following this, Pearson correlation coefficients were used for examining the relationship between stigma scales and continuous variables. One-way analysis of variance and independent sample $t$-tests were used for comparing the stigma scores across the categories of independent variables.

\section{Ethical considerations}

The research proposal was approved by the Ethical Review Committee of the Public Health and Medical Sciences College of Jimma University. A permission letter was obtained from the Jimma zone health department and the respective health care facilities. Written informed consent was also obtained from the study participants. The right of study participants to refuse participation or withdraw from the study at any point was respected. All accessed data were kept confidential. The names of the respondents were replaced with codes to ensure confidentiality.

\section{Results and discussion \\ Characteristics of the respondents}

Two hundred fifty-five health care providers participated in the survey (a response rate of 96.6\%), 156 (61.2\%) of whom were male. The majority $(72.2 \%)$ were from the Oromo ethnic group. One hundred eight (42.4\%) were Orthodox Christians, 160 (62.7\%) were nurses, and 171 (65.9\%) had diploma-level education. There were 113 (44.3\%) who had a monthly income less than or equal to 1233 Ethiopian birr (equivalent value in United States dollars [USD] \$72.96) (Table 1).

The average age of the participants was 27.2 years (standard deviation [SD] 5.72), ranging from 20 years to 49 years, and the average length of work experience was 4.76 years (SD 6.23), ranging from 1 month to
Table I Sociodemographic characteristics of health care providers, southwest Ethiopia, 20II ( $n=255)$

\begin{tabular}{|c|c|}
\hline Variable & No (\%) \\
\hline \multicolumn{2}{|l|}{ Sex } \\
\hline Male & I56 (6I.20) \\
\hline Female & $99(38.80)$ \\
\hline \multicolumn{2}{|l|}{ Age group } \\
\hline $20-24$ & $96(37.60)$ \\
\hline $25-29$ & $103(40.40)$ \\
\hline $30-34$ & $27(10.60)$ \\
\hline 35 years or more & $29(\mathrm{I} I .40)$ \\
\hline \multicolumn{2}{|l|}{ Marital status } \\
\hline Married & $125(49.00)$ \\
\hline Single & $125(49.00)$ \\
\hline Separated/widowed/divorced & $5(2.00)$ \\
\hline \multicolumn{2}{|l|}{ Ethnicity } \\
\hline Oromo & $187(73.30)$ \\
\hline Amhara & $34(13.30)$ \\
\hline Others $^{\mathrm{a}}$ & $34(13.30)$ \\
\hline \multicolumn{2}{|l|}{ Religion } \\
\hline Orthodox & $108(42.40)$ \\
\hline Protestant & $72(28.20)$ \\
\hline Muslim & $67(26.30)$ \\
\hline Others $^{\mathrm{b}}$ & $8(3.10)$ \\
\hline \multicolumn{2}{|l|}{ Perceived religiosity } \\
\hline Very religious & $59(23.10)$ \\
\hline Somewhat religious & $74(29.00)$ \\
\hline Nonreligious & $122(47.80)$ \\
\hline \multicolumn{2}{|l|}{ Professional category } \\
\hline Nurse/midwife & $160(62.70)$ \\
\hline Pharmacist/druggist & $30(11.80)$ \\
\hline Medical laboratory & $29(1 \mathrm{I} .40)$ \\
\hline Health officer & $27(10.60)$ \\
\hline Others ${ }^{c}$ & $9(3.50)$ \\
\hline \multicolumn{2}{|l|}{ Work experience } \\
\hline Less than 5 years & $186(72.90)$ \\
\hline 5 years or more & $69(27.10)$ \\
\hline \multicolumn{2}{|l|}{ Educational status } \\
\hline Diploma and certificate & $|7|(67.10)$ \\
\hline First degree and above & $84(32.90)$ \\
\hline \multicolumn{2}{|l|}{ Monthly income } \\
\hline 1233 Ethiopian birr (USD \$72.96) or less & II $3(44.30)$ \\
\hline 1234-2249 Ethiopian birr (USD \$73.02-\$133.08) & $80(31.40)$ \\
\hline 2550 Ethiopian birr (USD \$133.14) or more & $60(23.50)$ \\
\hline
\end{tabular}

Notes: ${ }^{\text {TTigre, Gurage, Dawro, Wolaita, Kambata, Yem, and Hadiya; 'Wakeffata and }}$ Catholic; 'Medical doctors, radiographers, and $\mathrm{X}$-ray technicians.

31 years. The average monthly income was 1631.36 birr (\$96.53), ranging from 700.00 birr $(\$ 41.42)$ to 4000.00 birr (\$236.69).

One hundred fifty-seven $(61.6 \%)$ of the survey participants had never attended training on topics related to SAD against PLHIV. A high proportion of participants, $151(76.1 \%)$ were from health centers. Respectively, 68 $(26.70 \%)$ and 99 (38.80\%) of participants had high basic HIV knowledge and in-depth HIV knowledge (Table 2). 
Table 2 HIV knowledge and institutional characteristics of health care providers, southwest Ethiopia, 20II $(n=255)$

\begin{tabular}{|c|c|}
\hline Variable & No (\%) \\
\hline \multicolumn{2}{|c|}{ Training on topics related to stigma and discrimination } \\
\hline None & $157(61.60)$ \\
\hline Once or more & $98(38.40)$ \\
\hline \multicolumn{2}{|l|}{ Basic HIV knowledge } \\
\hline High basic HIV knowledge & $68(26.70)$ \\
\hline Low basic HIV knowledge & $187(73.32)$ \\
\hline \multicolumn{2}{|l|}{ In-depth HIV knowledge } \\
\hline Had in-depth HIV knowledge & $99(38.80)$ \\
\hline No in-depth HIV knowledge & $156(6 \mid .20)$ \\
\hline \multicolumn{2}{|l|}{ HIV case load in the last 6 months } \\
\hline Ten or more clients & $69(27.10)$ \\
\hline Nine or fewer clients & $186(72.90)$ \\
\hline \multicolumn{2}{|l|}{ Type of health care facility } \\
\hline Hospital & $61(23.90)$ \\
\hline Health center & $194(76.10)$ \\
\hline \multicolumn{2}{|c|}{ Presence of ART service in the health care facility } \\
\hline Present & I5I (59.20) \\
\hline Absent & $104(40.80)$ \\
\hline
\end{tabular}

Abbreviations: ART, antiretroviral therapy; HIV, human immunodeficiency virus.

\section{Scale development}

\section{Perceived institutional support (PIS)}

During the EFA, three factors emerged from the PIS: perceived supply-related institutional support $(27.0 \%$ of the total variance), perceived policy-related institutional support (23.8\% of the variance), and perceived protocol-related institutional support (16.2\% of the total variance). All the items loaded on their respective factors (latent constructs) with the coefficients ranging from 0.58 to 0.90 (Table 3). The Cronbach's alphas of the three scales were $0.88,0.83$, and 0.89 , respectively.

\section{Stigma and discrimination against PLHIV}

SAD related to HIV/AIDS contained four dimensions: a fear dimension, a value-driven stigma, a discrimination dimension, and a disclosure dimension. ${ }^{1,15,30}$

During EFA, three factors emerged from the fear-driven stigma dimension. In this dimension, lack of feelings of safety, discomfort around PLHIV, and perceived workrelated HIV transmission explained $38.7 \%, 22.6 \%$, and $13.7 \%$ of the total variance, respectively. The numbers of the items were: eight for lack of feelings of safety, five for discomfort around PLHIV, and two for the fear of work-related HIV transmission. In general, factor loadings of the fear dimension items on their respective factors ranged from 0.58 to 0.90 (Table 4). The Cronbach's alphas of the three scales were $0.95,0.85$ and 0.88 , respectively (data not presented).

One significant factor emerged from the value-driven stigma, representing $68.0 \%$ of the total variance. This factor had seven components, with factor loadings of the seven items ranging from 0.75 to 0.86 (Table 5). The Cronbach's alpha of the scale was 0.92 (data not presented).

There were two factors that emerged from the discrimination dimension, which accounted for $35.7 \%$ and $32.1 \%$ of the total variance, respectively. The factors were named 'unethical treatment of PLHIV' and 'extra precaution'. Unethical treatment of PLHIV had four items. Extra precaution had three items. Generally, the factor loadings of the seven items ranged from 0.58 to 0.87 (Table 6). The Cronbach's alphas of the two scales were 0.80 and 0.81 , respectively (data not presented).

Only one component, accounting for $67.6 \%$ of the total variance, emerged from the unofficial disclosure dimension of stigma. The factor loadings of its five items ranged from

Table 3 Items used to measure perceived institutional support relating to HIV care by the health care providers, southwest Ethiopia, 20I I

\begin{tabular}{|c|c|c|c|}
\hline Items & Supply-related & Policy-related & Protocol-related \\
\hline Are sterile gloves readily available & 0.826 & & \\
\hline Are sterile needles readily available & 0.850 & & \\
\hline Is rubbing alcohol readily available? & 0.789 & & \\
\hline Is an autoclave readily available? & 0.645 & & \\
\hline Is a disposable container readily available? & 0.798 & & \\
\hline Is a supportive policy for PLHIV available? & & 0.893 & \\
\hline Is a policy supportive of PLHIV being implemented? & & 0.904 & \\
\hline Is a policy supportive of HCP who work with PLHIV available? & & 0.694 & \\
\hline Is a national HIV policy readily available for HCPs to use it? & & & 0.575 \\
\hline Is HIV counseling and testing readily available? & & & 0.765 \\
\hline Is a confidentiality protocol during HIV testing readily available? & & & 0.733 \\
\hline Is an informed consent protocol readily available? & & & 0.769 \\
\hline Is a precaution protocol readily available? & & & 0.768 \\
\hline Is a protocol for treatment of opportunistic infections readily available? & & & 0.736 \\
\hline Is a protocol for postexposure prophylaxis readily available? & & & 0.694 \\
\hline
\end{tabular}

Abbreviations: HCPs, health care providers; HIV, human immunodeficiency virus; PLHIV, people living with HIV. 
Table 4 Factor loadings of the items used to measure the fear-driven stigma dimension by the health care providers, southwest Ethiopia, 201I

\begin{tabular}{|c|c|c|c|}
\hline Items & $\begin{array}{l}\text { Lack of feelings } \\
\text { of safety }\end{array}$ & $\begin{array}{l}\text { Discomfort around } \\
\text { PLHIV }\end{array}$ & $\begin{array}{l}\text { Fear of work-related } \\
\text { HIV transmission }\end{array}$ \\
\hline Do you have fear of touching the sweat from PLHIV? & 0.805 & & \\
\hline Do you have fear of touching the saliva from PLHIV? & 0.796 & & \\
\hline Do you have fear of giving injections to PLHIV? & 0.832 & & \\
\hline Do you have fear of providing health care for PLHIV? & 0.732 & & \\
\hline Do you have fear of dressing the wounds of PLHIV? & 0.880 & & \\
\hline Do you have fear of conducting surgical procedure on PLHIV? & 0.869 & & \\
\hline Do you have fear of securing intravenous feed for PLHIV? & 0.880 & & \\
\hline I am comfortable with assisting or being assisted by PLHIV & & $0.74 I$ & \\
\hline I am not comfortable conducting surgical or invasive & 0.578 & & \\
\hline \multicolumn{4}{|l|}{ procedures on clients with unknown HIV status } \\
\hline I am not comfortable providing health services for PLHIV & & 0.672 & \\
\hline I am not comfortable sharing a bathroom with a colleague & & 0.693 & \\
\hline \multicolumn{4}{|l|}{ who is HIV-infected } \\
\hline Clients who are sex workers deserve the same level & & 0.803 & \\
\hline \multicolumn{4}{|l|}{ and quality of health care as other clients } \\
\hline $\begin{array}{l}\text { I avoid touching the clothing or belongings of clients known } \\
\text { or suspected to have HIV }\end{array}$ & & 0.654 & \\
\hline The most frequent mode of contracting HIV among HCPs & & & 0.902 \\
\hline \multicolumn{4}{|l|}{ is through work-related exposure } \\
\hline Most HIV-positive HCPs got infected at work & & & 0.871 \\
\hline
\end{tabular}

Abbreviations: HCPs, health care providers; HIV, human immunodeficiency virus; PLHIV, people living with HIV.

0.86 to 0.93 . The first item was dropped because of low factor loading (Table 7). This scale had a Cronbach's alpha of 0.93 after dropping the first item (data not presented).

The stigma scores were standardized as the percentage of the maximum scale scores to facilitate comparison, in case future researchers use a different number of items and/or a different number of response categories. These scores lie between $0-100 .^{43,44}$ The mean scale score was highest for the extra precaution scale, followed by the fear of work-related HIV transmission (Table 8).

\section{Construct validity}

To test the construct validities of the scales developed above, each scale was compared against a set of sociodemographic

Table 5 Factor loadings of the items used to measure the valuedriven stigma dimension by the health care providers, southwest Ethiopia, 201 I

\begin{tabular}{ll}
\hline Items to measure the value-driven stigma & $\begin{array}{l}\text { Value-driven } \\
\text { stigma }\end{array}$ \\
\hline HIV is a punishment from God & 0.749 \\
HIV is a punishment for bad behavior & 0.797 \\
People with HIV should be ashamed of themselves & 0.824 \\
Promiscuous men spread HIV in the community & 0.845 \\
Female prostitutes spread HIV & 0.849 \\
I would feel ashamed if I were infected with HIV & 0.836 \\
I would feel ashamed if my family were infected with HIV & 0.864 \\
\hline
\end{tabular}

Abbreviation: HIV, human immunodeficiency virus. and construct validity variables to determine the extent to which the scales performed in the expected manner. The factors that were associated with SAD in previous studies were used to check the construct validities of the health care providers' stigma scales. These factors included basic and in-depth HIV knowledge, ${ }^{3,8,15,30}$ HIV case load, ${ }^{30,42}$ previous training, $3,4,6,30,37,45,46$ PIS, ${ }^{7}$ and perceived religiosity. ${ }^{45}$ Although the directions were not consistent across all studies or all the dimensions of SAD, sex,,$^{37,45-47}$ age,,$^{37,45,46}$ and educational level, ${ }^{30,37,46}$ were also found to be associated with SAD in

Table 6 Factor loadings of the items used to measure the discrimination dimension of stigma by the health care providers, southwest Ethiopia, 201I

\begin{tabular}{lll}
\hline Items & $\begin{array}{l}\text { Unethical } \\
\text { treatment }\end{array}$ & $\begin{array}{l}\text { Extra } \\
\text { precaution }\end{array}$ \\
\hline $\begin{array}{l}\text { A client known or suspected } \\
\text { of having HIV receiving less care }\end{array}$ & 0.842 & \\
$\begin{array}{l}\text { Extra precaution for a client } \\
\text { suspected or known to have HIV }\end{array}$ & & 0.829 \\
Requiring clients to be tested & & 0.792 \\
for HIV before scheduling surgery & & \\
$\begin{array}{l}\text { Using latex glove for noninvasive } \\
\text { procedures }\end{array}$ & & 0.867 \\
$\begin{array}{l}\text { Assigning to junior HCPs } \\
\text { Testing without consent } \\
\text { HCPs gossiping about a client's }\end{array}$ & 0.845 & \\
HIV status & 0.792 & \\
\hline Ab & & \\
\hline
\end{tabular}

Abbreviations: $\mathrm{HCPs}$, health care providers; HIV, human immunodeficiency virus. 
Table 7 Factor loadings of the items used to measure the unofficial-disclosure dimension of SAD by health care providers, southwest Ethiopia, 20 I I

\begin{tabular}{ll}
\hline Items & Unofficial disclosure \\
\hline $\begin{array}{l}\text { Family member of the infected person told } \\
\text { the HCP of the staffs HIV status }\end{array}$ & 0.864 \\
$\begin{array}{l}\text { Community member told the staff of the } \\
\text { HCP's HIV status }\end{array}$ & 0.906 \\
$\begin{array}{l}\text { I heard about the HIV status of infected } \\
\text { staff through rumor and gossip }\end{array}$ & 0.865 \\
$\begin{array}{l}\text { I heard about the HIV status of the infected } \\
\text { staff from the HCP who tested him/her }\end{array}$ & 0.929 \\
I learned the HIV status from institution \\
records of the staff
\end{tabular}

Abbreviations: HCPs, health care providers; HIV, human immunodeficiency virus; $\mathrm{SAD}$, stigma and discrimination.

some previous studies. It was also shown that access to ART is a factor in reducing HIV-related stigma. ${ }^{48}$ Therefore, the relationship between the seven scales and independent variables were examined based on the existing conceptual knowledge of the determinants of HIV-related SAD.

The score for the lack of feelings of safety scale significantly varied between the health care providers who had high basic HIV knowledge and those health care providers who had low basic HIV knowledge $(\mathrm{t}=5.69, \mathrm{df}=253 ; P<0.01)$. The health care providers with high basic HIV knowledge had lower stigma scores when compared to those health care providers with low basic HIV knowledge (Table 9). This finding is consistent with previous studies. ${ }^{3,8,15}$ There was also a significant difference in the stigma scores (as measured by lack of feelings of safety) among the health care providers who had high HIV case loads, and those health care providers who had low HIV case loads $(\mathrm{t}=3.45, \mathrm{df}=253 ; P<0.01)$. The health care providers with high HIV case loads had lower stigma scores when compared to those health care providers with low HIV case loads (Table 9). Other studies also indicate similar findings. ${ }^{30,42}$

In addition, the stigma scores measured by this scale significantly varied with in-depth HIV knowledge $(\mathrm{t}=3.92$, $\mathrm{df}=253 ; P<0.01)$, attending training on topics related to SAD $(\mathrm{t}=3.15, \mathrm{df}=253 ; P<0.01)$ and the presence of ART in the health care facility $(\mathrm{t}=2.56, \mathrm{df}=253 ; P<0.05)$. The health care providers with in-depth HIV knowledge and those who had attended training on topics related to SAD had lower stigma scores when compared to those who did not have indepth HIV knowledge and who had not attended the trainings. In addition, those health care providers from facilities that offered ART services had lower stigma scores when compared to those facilities that did not have ART services (Table 9).
The perception of protocol-related institutional support $(P<0.01)$, the perception of supply-related institutional support $(P<0.05)$, and the perception of policy-related institutional support $(P<0.05)$ were negatively correlated with stigma scores measured by the lack of feelings of safety scale (Table 10). These findings are supported by the finding of the study conducted by Li et al. ${ }^{37}$

Similarly, the score for the discomfort around PLHIV scale significantly varied, with educational status $(\mathrm{t}=2.93$, df $=253 ; P<0.05)$, in-depth HIV knowledge $(\mathrm{t}=2.42$, $\mathrm{df}=253 ; P<0.01)$, attending training on topics related to $\mathrm{SAD}(\mathrm{t}=2.16, \mathrm{df}=253 ; P<0.05)$, and the presence of ART services $(\mathrm{t}=2.85, \mathrm{df}=253 ; P<0.01)$. Those health care providers with BSc or higher educational status had lower stigma scores when compared to their counterparts with a health diploma or lower (Table 11). Additionally, those health care providers who had in-depth HIV knowledge, and those who had attended training on topics related to SAD had lower stigma scores when compared to their counterparts. The health care providers from health care facilities rendering ART services also had lower stigma scores when compared to their counterparts (Table 9).

The respective perceptions of protocol-related institutional support $(P<0.05)$ and supply-related institutional support $(P<0.01)$ were also negatively correlated with the level of discomfort around PLHIV. It was also found that fear of work-related HIV transmission negatively correlated with the perception of policy-related institutional support $(P<0.05)$ (Table 10).

On the other hand, the stigma score measured by the value-driven scale significantly varied with in-depth HIV knowledge $(\mathrm{t}=3.62$, df $=253 ; P<0.01)$ and basic HIV knowledge $(\mathrm{t}=2.42, \mathrm{df}=253 ; P<0.05)$. Those health care providers with both in-depth HIV knowledge and high basic HIV knowledge had lower stigma scores when compared to their counterparts (Table 9). The value-driven stigma scale was also negatively correlated with the perception of protocol-related institutional support $(P<0.01)$, and the perception of supply-related institutional support $(P<0.01)$ (Table 10).

The score for unethical treatment of PLHIV also varied significantly with perceived religiosity $\left(\mathrm{F}=13.89, \mathrm{df}_{1}=2\right.$, $\left.\mathrm{df}_{2}=252 ; P<0.01\right)$. Post-hoc multiple comparisons using the Bonferroni method indicated that those health care providers who claimed to be very religious scored an average of 0.80 (95\% confidence interval [CI]: 0.43-1.16) units higher on the stigma scores than those who claimed to be nonreligious $(P<0.01)$. Also, the health care providers who claimed to 


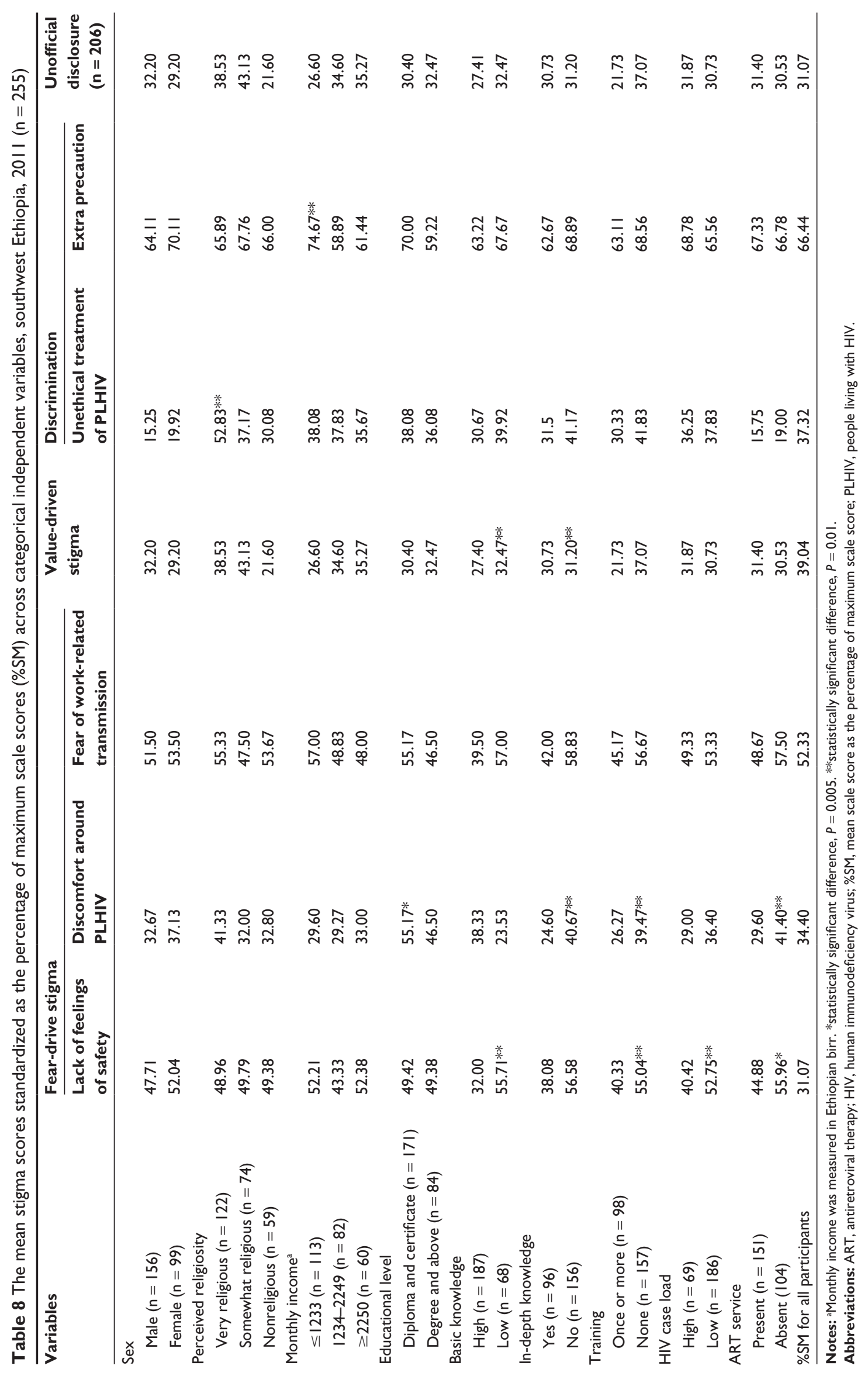


Table 9 The comparisons of the stigma scores (measured by the fear-driven and value-driven stigma dimensions) across independent variables, southwest Ethiopia, $20 \mathrm{II}(\mathrm{n}=255)$

\begin{tabular}{|c|c|c|c|c|c|c|c|c|c|c|c|c|}
\hline \multirow{4}{*}{$\begin{array}{l}\text { Variables } \\
\text { Educational status }^{\mathrm{a}}\end{array}$} & \multicolumn{9}{|c|}{ Fear-driven stigma } & \multirow{2}{*}{\multicolumn{3}{|c|}{ Value-driven stigma }} \\
\hline & \multicolumn{3}{|c|}{$\begin{array}{l}\text { Lack of feelings } \\
\text { of safety }\end{array}$} & \multicolumn{3}{|c|}{$\begin{array}{l}\text { Discomfort around } \\
\text { PLHIV }\end{array}$} & \multicolumn{3}{|c|}{$\begin{array}{l}\text { Fear of work-related } \\
\text { HIV transmission }\end{array}$} & & & \\
\hline & \multirow{2}{*}{$\frac{\text { MD }}{-0.16}$} & \multicolumn{2}{|c|}{$95 \% \mathrm{Cl}$} & \multirow{2}{*}{$\frac{\text { MD }}{0.38 *}$} & \multicolumn{2}{|c|}{$95 \% \mathrm{Cl}$} & \multirow{2}{*}{$\begin{array}{l}\text { MD } \\
0.19\end{array}$} & \multicolumn{2}{|c|}{$95 \% \mathrm{Cl}$} & \multirow{2}{*}{$\frac{\text { MD }}{0.23}$} & \multicolumn{2}{|c|}{$95 \% \mathrm{Cl}$} \\
\hline & & -0.43 & 0.10 & & 0.13 & 0.64 & & -0.07 & 0.45 & & -0.01 & 0.47 \\
\hline Basic HIV knowledge & $0.76 * *$ & 0.54 & 0.98 & 0.14 & -0.11 & 0.38 & 0.21 & -0.07 & 0.49 & $0.34 * *$ & 0.06 & 0.61 \\
\hline In-depth HIV knowledge & $0.49 * *$ & 0.24 & 0.74 & $0.45 * *$ & 0.22 & 0.69 & 0.25 & -0.00 & 0.50 & $0.45 * *$ & 0.22 & 0.69 \\
\hline HIV case load & $0.48 * *$ & 0.20 & 0.75 & 0.08 & -0.20 & 0.36 & -0.08 & -0.39 & 0.24 & 0.10 & -0.18 & 0.38 \\
\hline Training on SAD & $0.40 * *$ & 0.15 & 0.65 & $0.28^{*}$ & 0.24 & 0.53 & 0.15 & -0.11 & 0.40 & 0.13 & -0.05 & 0.46 \\
\hline ART & $0.32^{*}$ & 0.08 & 0.57 & $0.36 * *$ & 0.11 & 0.61 & 0.08 & -0.17 & 0.33 & 0.14 & -0.11 & 0.40 \\
\hline
\end{tabular}

Notes: aFirst degree and above was compared to diploma and certificate. The groups with low basic HIV knowledge, low HIV case load, no training, and the groups from areas where ART service was not present had higher stigma scores than their respective counterparts. *statistically significant at $P=0.05$; **statistically significant at $P=0.01$.

Abbreviations: ART, antiretroviral therapy; CI, confidence interval; HIV, human immunodeficiency virus; MD, mean difference; PLHIV, people living with HIV; SAD, stigma and discrimination.

be very religious had an average of 0.49 (95\% CI: 0.89-0.90) units higher on the stigma scores when compared to those who claimed to be only somewhat religious $(P<0.05)$ (data not presented). This finding is consistent with the findings of the study by Andrewin and Chien. ${ }^{45}$ The unethical treatment of PLHIV also negatively correlated with the perception of protocol-related institutional support $(P<0.01)$ and work experience in years $(P<0.05)$ (Table 10).

The score for the extra precaution scale significantly varied with educational status $(\mathrm{t}=2.86, \mathrm{df}=253 ; P<0.01)$. Those health care providers with an educational level of BSc or higher had lower stigma scores when compared to their counterparts who had an education level lower than health diploma (Table 11). The stigma scores measured by the extra precaution scale varied with monthly income category $\left(\mathrm{F}=8.63, \mathrm{df}_{1}=2\right.$, $\left.\mathrm{df}_{2}=252 ; P<0.01\right)$. Post-hoc comparisons of stigma scores in the extra precaution scale indicated that health care providers with a monthly income of 1233 Ethiopian birr (equivalent to USD $\$ 72.96$ or less) had an average 0.56 units (95\% CI: 0.169-0.963) and higher stigma scores when compared to those health care providers with a monthly income of 1234-2249 birr (\$73.02-133.08) $(P<0.01)$ (data not presented).
The score for the unofficial disclosure scale varied significantly with training on topics related to $\mathrm{SAD}(\mathrm{t}=3.07$, $\mathrm{df}=204 ; P<0.01)$. Those health care providers who had attended training on topics related to SAD had lower stigma scores when compared to those who did not attend the training (Table 11). The unofficial disclosure scale was also negatively correlated with the perception of protocol-related institutional support $(P<0.01)$ (Table 10). Moreover, the score for the unofficial disclosure scale significantly varied with perceived religiosity $\left(\mathrm{F}=8.50, \mathrm{df}_{1}=2, \mathrm{df}_{2}=203\right.$; $P<0.01)$. Post-hoc comparisons using the Bonferroni correction indicated that those health care providers who claimed to only be somewhat religious had an average increase of 0.61 (95\% CI: 0.23-0.99) in their stigma scores when compared to those who rated themselves nonreligious $(P<0.05)$. On average, those health care providers who rated themselves as very religious had a stigma score 0.48 higher $(95 \%$ CI: $0.06-0.89)$ than those who claimed to be nonreligious $(P<0.05)$ (data not presented). These findings are consistent with the study by Andrewin and Chien. ${ }^{45}$

In our study, there was no significant difference in the stigma scores on all scales across sex categories.

Table 10 The correlation of the perceived institutional support and work experience with SAD by the health care providers, Jimma zone, southwest Ethiopia, 20II ( $n=255)$

\begin{tabular}{|c|c|c|c|c|c|c|c|}
\hline Variables & $\begin{array}{l}\text { The lack } \\
\text { of feelings } \\
\text { of safety }\end{array}$ & $\begin{array}{l}\text { Discomfort } \\
\text { around } \\
\text { PLHIV }\end{array}$ & $\begin{array}{l}\text { The fear of } \\
\text { work-related } \\
\text { HIV exposure }\end{array}$ & $\begin{array}{l}\text { Value-driven } \\
\text { stigma }\end{array}$ & $\begin{array}{l}\text { Unethical } \\
\text { treatment } \\
\text { of PLHIV }\end{array}$ & $\begin{array}{l}\text { Extra } \\
\text { precautions }\end{array}$ & $\begin{array}{l}\text { Unofficial } \\
\text { disclosure }\end{array}$ \\
\hline Protocol & $-0.19 * *$ & $-0.16^{*}$ & -0.01 & $-0.18^{* *}$ & $-0.18^{* *}$ & -0.001 & $-0.19 * *$ \\
\hline Supply & $-0.16^{*}$ & $-0.27 * *$ & -0.09 & $-0.21 * *$ & -0.08 & 0.01 & -0.13 \\
\hline Policy & $-0.15^{*}$ & -0.06 & $-0.14^{*}$ & -0.03 & 0.05 & 0.07 & 0.09 \\
\hline Experience (years) & -0.12 & 0.01 & 0.07 & 0.03 & $-0.15^{*}$ & 0.01 & -0.09 \\
\hline
\end{tabular}

Notes: *Statistically significant correlation, $P=0.05$; ** statistically significant correlation, $P=0.01$.

Abbreviations: HIV, human immunodeficiency virus; PLHIV, people living with HIV; SAD, stigma and discrimination. 
Table II The comparisons of stigma scores (measured by discrimination and disclosure dimensions) across independent variables, southwest Ethiopia, 20II

\begin{tabular}{|c|c|c|c|c|c|c|c|c|c|}
\hline \multirow{4}{*}{$\begin{array}{l}\text { Variables } \\
\text { Educational status }^{\mathrm{a}}\end{array}$} & \multicolumn{6}{|c|}{ Discrimination dimension $(n=255)$} & \multirow{2}{*}{\multicolumn{3}{|c|}{$\begin{array}{l}\text { Disclosure dimension } \\
(n=206)\end{array}$}} \\
\hline & \multicolumn{3}{|c|}{ Unethical treatment of PLHIV } & \multicolumn{3}{|c|}{ Extra precaution } & & & \\
\hline & \multirow{2}{*}{$\frac{\text { MD }}{-0.16}$} & \multicolumn{2}{|c|}{$95 \% \mathrm{Cl}$} & \multirow{2}{*}{$\begin{array}{l}\text { MD } \\
-0.38^{*}\end{array}$} & \multicolumn{2}{|c|}{$95 \% \mathrm{Cl}$} & \multirow{2}{*}{$\frac{\text { MD }}{-0.056}$} & \multicolumn{2}{|l|}{$95 \% \mathrm{Cl}$} \\
\hline & & -0.42 & 0.11 & & 0.12 & 0.63 & & -0.36 & 0.24 \\
\hline Basic HIV knowledge & 0.02 & -0.24 & 0.28 & 0.08 & -0.21 & 0.38 & 0.14 & -0.17 & 0.44 \\
\hline In-depth HIV knowledge & -0.01 & -0.03 & 0.24 & 0.16 & -0.09 & 0.42 & -0.01 & -0.27 & 0.30 \\
\hline HIV case load & -0.10 & -0.37 & 0.18 & -0.07 & -0.35 & 0.21 & -0.03 & -0.35 & 0.28 \\
\hline Training on SAD & 0.20 & -0.04 & 0.44 & 0.07 & -0.18 & 0.33 & $0.43 *$ & 0.15 & 0.70 \\
\hline ART service present & -0.13 & -0.38 & 0.12 & 0.05 & -0.20 & 0.30 & -0.023 & -0.14 & 0.30 \\
\hline
\end{tabular}

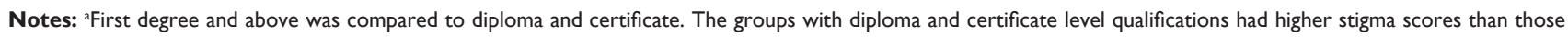
with degree and above educational level. *statistically significant, $P=0.01$.

Abbreviations: ART, antiretroviral therapy; Cl, confidence interval; HIV, human immunodeficiency virus; MD, mean difference; PLHIV, people living with HIV; SAD, stigma and discrimination.

This finding is inconsistent with some previous studies; $;^{37,45-47}$ however, it is in line with those studies conducted to develop stigma indices. . $^{15,30}$

In our current study, the health care providers' HIVrelated stigma scale demonstrated good psychometric properties. The construct validities of the scales were tested using construct validity variables, and they trended in the direction expected based on conceptual knowledge. ${ }^{15,30}$ This provides further evidence that the scales designed to assess fear- and value-driven stigma, discrimination and unofficial disclosure do in fact accurately measure the constructs intended, and are rigorous enough to use in similar settings. Additionally, the internal consistencies of the scales were found to be good-to-excellent. ${ }^{40,41}$

However, in the current study, one scale emerged from the value-driven stigma, and two scales emerged from the discrimination dimension of stigma. The first scale of the discrimination dimension addresses how health care providers informally treat PLHIV. It was, therefore, named 'unethical treatment of PLHIV'. The second scale of the discrimination dimension addressed issues related to extra precautions. In addition, only two items were loaded on the fear of workrelated HIV exposure scale. In the Internet-based study conducted by the USAID, the work-related HIV transmission scale had three items. The third item was 'before examining a patient with HIV, I put on a protective mask'. This item was not applicable to our study context for two reasons: (1) in the health care district settings of Ethiopia, it is not usual practice to put on masks, as masks are only available in operating theatres, and (2) during the pretest, this item was rejected by the study participants, and we were therefore forced to remove this item from the questionnaire. Our decision not to drop the entire scale, or merge it with another scale was due to the fact that the two items had high factor loadings on the scale. Additionally, the items did not load on other scales, and so we decided to retain the scale.

\section{Conclusions}

In this study, seven scales emerged from the four dimensions of stigma during the EFA. Since they showed good construct validities and internal consistencies, they are assets for future research on SAD of PLHIV by health care providers. However, it is worth noting that the current study was conducted in health centers and a district hospital, both of which settings are part of the primary health care unit in the country's health system. The results should therefore be interpreted with caution while bearing these settings and their respective employed health care providers in mind. Hence, further study is recommended to test the validity and reliability of the scales at other levels of the health system, both in Ethiopia and elsewhere in the world. Future studies may also explore experienced stigma, an issue not addressed by the current study. The research team did not include it in the current study because within the Ethiopian context, whether health care providers are stigmatized as a result of working with PLHIV is unknown. Additionally, we would recommend that future researchers include additional items on the fear of work-related HIV transmission.

\section{Author contributions}

GTF was involved in the design of the study, data analysis, and interpretation of the findings, and prepared both the manuscript and the report. LA was involved in the design of the study, data analysis, and review of the report. EG was involved in the design of the study, analysis and 
interpretation of the data, and review of the report. MW was involved in the study design, analysis and interpretation of the data, and writing and review of the report and manuscript. All the authors have read and agreed on the final manuscript.

\section{Acknowledgments}

We would like to thank the Oromia Regional Health Bureau and Jimma University for funding the study. Our heartfelt thanks go to the study participants, supervisors, and data collectors. We are also grateful to Dr Charlotte Hanlon for editing the final manuscript.

\section{Disclosure}

The authors declare that they have no conflicts of interest in this work.

\section{References}

1. Nyblade L, MacQuarrie K. Can We Measure HIV/AIDS-related Stigma and Discrimination? Current Knowledge About Quantifying Stigma in Developing Countries. Washington, DC: United States Agency for International Development; 2006. Available from: http://www.policyproject.com/pubs/generalreport/Measure\%20HIV\%20Stigma.pdf. Accessed February 27, 2012.

2. Parker R, Aggleton P. HIV and AIDS-related stigma and discrimination: a conceptual framework and implications for action. Soc Sci Med. 2003;57(1):13-24.

3. Banteyerga H, Kidanu A, Abebe F, et al. Perceived Stigmatization and Discrimination by Healthcare Providers towards Persons with HIV/ AIDS. Addis Ababa, Ethiopia: Miz-Hasab Research Center, IntraHealth International, USAIDS; 2005.

4. Letemo G. The discriminatory attitudes of health providers against people living with HIV. PLoS Med. 2005;2(8):e246.

5. Adebajo SB, Bamgbala AO, Oyediran MA. Attitudes of health care providers to persons living with HIV/AIDS in Lagos State, Nigeria. Afr J Reprod Health. 2003;7(1):103-112.

6. Reis C, Heisler M, Amowitz LL, et al. Discriminatory attitudes and practices by health workers towards patients with HIV/AIDS in Nigeria. PLoS Med. 2005;2(8):e246.

7. Sadoh AE, Fawole AO, Sadoh WE, Oladimeji AO, Sotiloye OS. Attitude of health-care workers to HIV/AIDS. Afr J Reprod Health. 2006;10(1):39-46.

8. Mahendra VS, Gilborn L, Bharat S, et al. Understanding and measuring AIDS-related stigma in health care settings: a developing country perspective. SAHARA J. 2007;4(2):616-625.

9. Banteyerga H, Kidanu A, Nyblade L, MacQuarrie K, Pande R. Yichalaliko! It can be done! Exploring HIV and AIDS stigma and related discrimination in Ethiopia: Causes, manifestations, consequences and coping mechanism in Ethiopia. Addis Ababa, Ethiopia: Miz-Hasab Research Center; 2004. Available from: http://miz-hasab.org/report/ Yichalalko_\%20Ethiopia_Exploring\%20HIV\%20and\%20AIDS\%20 Stigma\%20and\%20Related\%20Discrimination\%20in\%20Ethiopia. doc. Accessed February 27, 2012.

10. Li L, Wu Z, Zhao Y, Lin C, Detels R, Wu S. Using case vignettes to measure HIV-related stigma among health professionals in China. Int J Epidemiol. 2007;36(1):178-184.

11. Varas-Diaz N, Neilands TB. Development and validation of a culturally appropriate HIV/AIDS stigma scale for Puerto Rican health professionals in training. AIDS Care. 2009;21(10):1259-1270.
12. Herek GM, Mitnick L, Burris S, et al. Workshop report: AIDS and stigma: a conceptual framework and research agenda. AIDS Public Policy J. 1998;13(1):36-47.

13. US Agency for International Development (USAID) Health Policy Initiative, Task Order 1. Stigmatization and Discrimination of HIVpositive People by Providers of General Medical Services in Ukraine. Washington, DC: Futures Group, Health Policy Initiative, Task Order 1; 2007. Available from: http://pdf.usaid.gov/pdf_docs/PNADM170. pdf. Accessed February 27, 2012.

14. Kamau J, Odundo P, Korir J. Measuring the Degree of Stigma and Discrimination in Kenya: An index for HIV/AIDS facilities and providers. Washington, DC: Futures Group, Health Policy Initiative, Task Order 1; 2007. Available from: http://www.hrhresourcecenter.org/ node/2888. Accessed February 27, 2012.

15. Nyblade L, MacQuarrie K, Phillip F, et al; Tanzania Stigma-Indicators Field Test Group. Working Report Measuring HIV Stigma: Results of a field test in Tanzania. Washington, DC: The Synergy Project, USAID; 2005. Available from: http://www.icrw.org/files/publications/WorkingReport-Measuring-HIV-Stigma-Results-of-a-Field-Test-in-Tanzania. pdf. Accessed February 27, 2012.

16. Ford K, Wirawan DN, Sumantera GM, Sawitri AA, Stahre M. Voluntary HIV testing, disclosure, and stigma among injection drug users in Bali, Indonesia. AIDS Educ Prev. 2004;16(6):487-498.

17. Sayles JN, Wong MD, Kinsler JJ, Martins D, Cunningham WE. The association of stigma and self-reported access to medical care and antiretroviral therapy adherence in persons living with HIV/AIDS. J Gen Intern Med. 2009;24(10):1101-1108.

18. Gari T, Habte D, Markos E. HIV positive status disclosure among young women attending ART clinic at Hawassa University Referral Hospital, South Ethiopia. East Afr J Public Health. 2010;7(1):89-91.

19. Wolfe WR, Weiser SD, Bangsberg DR, et al. Effects of HIV-related stigma among an early sample of patients receiving antiretroviral therapy in Botswana. AIDS Care. 2006;18(8):931-933.

20. Obermeyer CM, Osborn M. The utilization of testing and counseling for HIV: a review of the social and behavioral evidence. Am J Public Health. 2007;97(10):1762-1774.

21. Calin T, Green J, Hetherton J, Brook G. Disclosure of HIV among Black African men and women attending a London HIV clinic. AIDS Care. 2007;19(3):385-391.

22. Davey G, Teklu T. Which factors influence North Ethiopian adults' use of dual protection from unintended pregnancy and HIV/ AIDS? Ethiopian Journal of Health Development. 2006;22(3): 226-231.

23. Bond V, Chase E, Aggleton P. Stigma, HIV/AIDS and prevention and mother-to-child transmission in Zambia. Eval Program Plann. 2002; 25(4):347-356.

24. Nyblade L, Field-Nguer ML. Women, Communities and the Prevention of Mother-to-Child Transmission of HIV: Issues and Findings from Community Research in Botswana and Zambia. Washington, DC: International Center for Research on Women; 2001. Available from: http://www.popcouncil.org/pdfs/mtcticrw.pdf. Accessed February 28, 2012.

25. Joint United Nations Programme for HIV/AIDS on HIV/AIDS (UNAIDS). Reducing HIV Stigma and Discrimination: A critical part of national AIDS programmes. Geneva, Switzerland: Joint United Nations Programme on HIV/AIDS; 2007.

26. Gupta G, Nyblade L. Turn the tide: Tackling HIV stigma and discrimination. In: Commonwealth Health Ministers Book. London, UK; Commonwealth Secretariat; 2007:190-193.

27. Dieleman M, Biemba G, Mphuka S, et al. 'We are also dying like any other people, we are also people': perceptions of the impact of HIV/ AIDs on health workers in two districts in Zambia. Health Policy Plan. 2007;22(3):139-148.

28. Uebel KE, Nash J, Avalos A. Caring for the caregivers: Models of HIV/ AIDS care and treatment provision for healthcare workers in Southern Africa. J Infect Dis. 2007;196(Suppl 3):S500-S504. 
29. Nyblade L, Stangl A, Weiss E, Ashburn K. Combating HIV stigma in health care settings: what works? J Int AIDS Soc. 2009;6:12-15.

30. UNAIDS Health Policy Initiative, Task Order 1. Measuring the Degree of HIV-related Stigma and Discrimination in Health Facilities and Providers: Working Report. Washington, DC: Futures Group, Health Policy Initiative, Task Order 1. 2010. Available from: http://www.healthpolicyinitiative.com/Publications/Documents/1312_1_Health_Facility_and_Provider_Stigma_Measurement_Tool_.pdf. Accessed February 27, 2012.

31. Federal HIV/AIDS Prevention and Control Office. Strategic Plan for Intensifying Multi-sectoral HIV/AIDS Response (2004-2008). Addis Ababa, Ethiopia: Federal HIV/AIDS Prevention and Control Office; 2004. Available from: http://siteresources.worldbank.org/INTHIVAIDS/ Resources/375798-1151090631807/2693180-1151090665111/269318 1-1155742859198/Ethiopia.pdf. Accessed February 27, 2012.

32. Federal Democratic Republic of Ethiopia, Ministry of Health. HIV/AIDS and the Health-related Millennium Development Goals: The experience in Ethiopia. Addis Ababa, Ethiopia: Federal Democratic Republic of Ethiopia, Ministry of Health; September, 2010. Available from: http:// data.unaids.org/pub/Report/2010/20100917_ethiopia_aids_plus_mdgs_ en.pdf. Accessed February 27, 2012.

33. Federal HIV/AIDS Prevention and Control Office. Report on Progress towards Implementation of the UN Declaration of Commitment on HIV/AIDS. Addis Ababa, Ethiopia: Federal HIV/AIDS Prevention and Control Office; 2010.

34. Federal Democratic Republic of Ethiopia, Ministry of Health. Accelerated Access to HIV/AIDS Prevention, Care and Treatment in Ethiopia. Road map 2007-2010. Addis Ababa, Ethiopia: Federal Democratic Republic of Ethiopia, Ministry of Health; 2007.

35. Ethiopian Federal Civil Servants Proclamation No. 262/2002. Federal Negarit Gazeta. Jan 2002;8:1670.

36. Ethiopian Federal Civil Service Proclamation No. 515/2007. Federal Negarit Gazeta. February 19, 2007;15:3540.
37. Li L, Wu Z, Wu S, Zhaoc Y, Jia M, Yan Z. HIV-related stigma in health care settings: a survey of service providers in China. AIDS Patient Care STDS. 2007;21(10):753-762.

38. Anderson J, Gerbing D. Predicting the performance of measures in a confirmatory factor analysis with a pretest assessment of their substantive validities. J App Psych. 1991;76(5):732-740.

39. Hair J, Anderson R, Tatham, R, Black W. Multivariate Data Analysis. 5th ed. Englewood Cliffs, NJ: Prentice-Hall, Inc; 1998.

40. Nunnally J. Psychometric Theory. 2nd ed. New York, NY: McGraw Hill; 1978.

41. George D, Mallery P. SPSS for Windows Step by Step: A simple guide and reference. 11.0 update. 4th ed. Boston, MA: Allyn and Bacon; 2003.

42. Massiah E, Roach TC, Jacobs C, et al. Stigma, discrimination, and HIV/ AIDS knowledge among physicians in Barbados. Rev Panam Salud Publica. 2004;16(6):395-401.

43. Reidpath DD, Chan KY. A method for the quantitative analysis of the layering of HIV related stigma. AIDS Care. 2005;17(4):425-432.

44. Cummins RA. On the trail of the gold standard for subjective well-being. Soc Indic Res. 1995;35:179-200.

45. Andrewin A, Chien LY. Stigmatization of patients with HIV/AIDS among doctors and nurses in Belize. AIDS Patient Care STDs. 2008; 22(11):897-906.

46. Hossain MB, Kippax S. HIV-related discriminatory attitudes of healthcare workers in Bangladesh. J Health Popul Nutr. 2010;28(2):199-207.

47. Umeh CN, Essien EJ, Ezedinachi EN, Ross MW. Knowledge, beliefs and attitudes about HIV/AIDS-related issues, and the sources of knowledge among health care professionals in southern Nigeria. $J R$ Soc Promot Health. 2008;128(5):233-239.

48. Wolfe WR, Weiser SD, Leiter K, et al. The impact of universal access to antiretroviral therapy on HIV stigma in Botswana. Am J Public Health. 2008;98(10):1865-1871. 


\section{Appendix I}

\section{Survey questionnaire for health care providers (English version)}

Jimma University College of Medical Sciences and Public Health

Informed consent

Dear sir/madam (Dr),

We are conducting research on stigma and discrimination against people living with HIV/AIDS among health care providers. To aid us in our research, we would like you to respond to this questionnaire truthfully. The information that we will obtain will be used only for research purposes. We assure you that confidentiality is of primary importance. There is no risk to you or your organization in this study apart from the time spent answering questions. We politely request your cooperation in responding to our questionnaire. You have the right not to respond at all or to withdraw in the meantime, but your input will have great value for the success of our objective. Do you agree to respond to this questionnaire? If so, indicate your agreement with your signature.

Name

Signature Date __ Month __ Year

Thank you for your cooperation!

\section{Questionnaire for the study on stigma and discrimination against people living with HIVIAIDS among health care providers in health care facilities of Jimma zone, 20 I I \\ Questionnaire No. Data collector's name signature \\ Supervisor's name signature \\ Date filled \\ Name of the health care institution name of the unit/department}

\section{Part I}

\section{Questions about sociodemographic characteristics}

The following questions are related to sociodemographic characteristics. Please respond to the questions based on the nature of each question.

\begin{tabular}{lll} 
No & Question & Options \\
\hline I. & Age & \multicolumn{1}{c}{ years } \\
2. & Sex & A. Male B. Female \\
3. & Marital status & $\begin{array}{c}\text { A. Married B. Divorced/separated C. Widowed D. Single } \\
\text { birr }\end{array}$ \\
4. & Menthly income & A. Orthodox B. Muslim C. Protestant D. Catholic E. Others, please specify, \\
6. & Religion & A. Very religious B. Somewhat religious C. Not religious \\
7. & Ethnicity & A. Oromo B. Amhara C. Tigre D. Gurage \\
8. & Qualification & D. Dawro E. Others, please specify, \\
9. & Profession & A. Nurse/midwife B. Medical doctor \\
& & C. Health officer D. Laboratory technologist \\
& & E. Pharmacist/druggist F. Others, please specify, \\
\hline
\end{tabular}

\section{Part II}

\section{Personal knowledge, experience, and institutional factors}

The followings are questions relating to the knowledge and experience of the health care provider, and institutional factors in which the health care provider operates. Please respond to each question genuinely. 
10. Years of experience

II. Have you ever participated in any training related to HIVIAIDS stigma and discrimination?

12. What type of service do you provide in this health care institution?

13. How many times did you participate in training related to HIVIAIDS stigma and discrimination?

14. Have you given health care service for HIVIAIDS clients in the last 6 months?

15. If yes, for how many HIVIAIDS clients did you give health care service in the last 6 months?

Indicate whether the following statements are correct or not, by choosing yes or no or I do not know alternatives.

16. The risk of HIV transmission following needle-prick or sharps injuries is small (approximately I in 300)

17. The risk of HIV transmission following a splash of blood to nonintact skin or mucus membrane is very small (approximately I in 1000)

18. Standard sterilization procedures are sufficient when sterilizing instruments used on an HIV-positive client _years and __months

A. Yes B. No

- times

A. Yes B. No C. I do not know

_clients

A. Yes B. I do not know

C. No

A. Yes B. I do not know

C. No

A. Yes B. I do not know

C. No

19. Which of the following body fluids have high enough concentrations of HIV to transmit the virus? (Identify all that can transmit HIV by encircling the options).

A. Saliva B. Blood C. Urine D. Feces E. Spinal fluid F. Semen G. Breast milk H. Vaginal secretions I. Pus

K. Sweat L. Pleural fluid M. Tears

20. Which of the following body fluids do not have high enough concentration of HIV to transmit the virus? (Identify all that can transmit HIV by encircling the options).

A. Saliva B. Blood C. Urine D. Feces E. Spinal fluid F. Semen G. Breast milk H. Vaginal secretions I. Pus

K. Sweat L. Pleural fluid M. Tears

The following questions are related to factors in health care institutions. Choose among the given options for each of them.

21. Are the following facilities/equipment always available in this health care institution

2I.I Sterile gloves

$21.2 \quad$ Sterile needles

21.3 Rubbing alcohol

21.4 Autoclave for daily use

21.5 Disposable containers

22. Does your health care facility have a policy to protect HIV-positive clients against discrimination?

23. If so, is the policy being enforced?

24. Does this health care facility have incentives for health care providers who work with HIV/AIDS clients?

25. Are the following protocols readily available in your health care facility?

25.I National HIV policy

25.2 HIV counseling and testing

25.3 Confidentiality

25.4 Informed consent

25.5 Universal precautions

25.6 Treatment of opportunistic infections

25.7 Postexposure prophylaxis
A. No B. Not sure C. Yes A. No B. Not sure C. Yes A. No B. Not sure C. Yes A. No B. Not sure C. Yes A. No B. Not sure C. Yes A. No B. Not sure C. Yes A. No B. Not sure C. Yes A. No B. Not sure C. Yes

A. No B. Not sure C. Yes A. No B. Not sure C. Yes A. No B. Not sure C. Yes A. No B. Not sure C. Yes A. No B. Not sure C. Yes A. No B. Not sure C. Yes A. No B. Not sure C. Yes

\section{Part III}

\section{Questions related to reactions with PLHIV}

Please, indicate if you have strong fear of HIV transmission, if you have fear of HIV transmission, do not have fear of HIV transmission, or if you will never have fear of HIV transmission in the following circumstances.

\begin{tabular}{lll}
\hline No & Question & Option \\
\hline 26. & Touching the sweat of a person with HIV or AIDS & A. I have strong fear of HIV transmission \\
& & B. I have fear of HIV transmission \\
& C. I do not have fear of HIV transmission \\
27. & D. I will never have fear of HIV transmission \\
& Touching the saliva of a person with HIV or AIDS? & A. I have strong fear of HIV transmission \\
& B. I have fear of HIV transmission \\
& C. I do not know if I have fear of HIV \\
& transmission
\end{tabular}


28. Giving an injection to a person with HIV or AIDS?

29. Caring for a person with HIV or AIDS?

30. Dressing the wounds of a person with HIV or AIDS?

31. Conducting surgery on or suturing a person with HIV or AIDS?

32. Putting an intravenous drip in someone who is showing signs of AIDS?

Do you strongly agree, agree, disagree or strongly disagree with each statement? No Question

33. I am not comfortable assisting or being assisted by a colleague who is HIV-infected

34. I am comfortable performing surgical or invasive procedures on clients whose HIV status is unknown?

35. I am comfortable providing health services to clients who are HIV-positive?

36. I am not comfortable sharing a bathroom with a colleague who is HIV-infected

37. Clients who are sex workers deserve to receive the same level and quality of health care as other clients

38. I avoid touching the clothing and belongings of clients known or suspected to have HIV for fear of becoming HIV-infected

39. The most frequent mode of contracting HIV among health care providers is through work-related exposure

40. Most HIV-positive health care providers get infected at work

4I. HIV is a punishment from God

42. HIV is punishment for bad behavior

43. People with HIV should be ashamed of themselves

44. Promiscuous men spread HIV in our community

45. Female prostitutes spread HIV

46. I would feel ashamed if I was infected with HIV

47. I would feel ashamed if someone in my family was infected with HIV
A. I have strong fear of HIV transmission

B. I have fear of HIV transmission

C. I do not have fear of HIV transmission

D. I will never have fear of HIV transmission

A. I have strong fear of HIV transmission

B. I have fear of HIV transmission

C. I do not have fear of HIV transmission

D. I will never have fear of HIV transmission

A. I have strong fear of HIV transmission

B. I have fear of HIV transmission

C. I do not have fear of HIV transmission

D. I will never have fear of HIV transmission

A. I have strong fear of HIV transmission

B. I have fear of HIV transmission

C. I do not have fear of HIV transmission

D. I will never have fear of HIV transmission

A. I have strong fear of HIV transmission

B. I have fear of HIV transmission

C. I do not have fear of HIV transmission

D. I will never have fear of HIV transmission
Option

A. Disagree strongly B. Disagree

C. Agree D. Agree strongly

A. Disagree strongly B. Disagree

C. Agree D. Agree strongly

A. Disagree strongly B. Disagree

C. Agree D. Agree strongly

A. Disagree strongly B. Disagree C. Agree

D. Agree strongly

A. Disagree strongly B. Disagree

C. Agree D. Agree strongly

A. Disagree strongly B. Disagree

C. Agree D. Agree strongly

A. Disagree strongly B. Disagree

C. Agree D. Agree strongly

A. Disagree strongly B. Disagree

C. Agree D. Agree strongly

A. Disagree strongly B. Disagree

C. Agree D. Agree strongly

A. Disagree strongly B. Disagree

C. Agree D. Agree strongly

A. Disagree strongly B. Disagree

C. Agree D. Agree strongly

A. Disagree strongly B. Disagree

C. Agree D. Agree strongly

A. Disagree strongly B. Disagree

C. Agree D. Agree strongly

A. Disagree strongly B. Disagree

C. Agree D. Agree strongly

A. Disagree strongly B. Disagree

C. Agree D. Agree strongly

In the past 12 months, have you seen or observed the following situations happening in this health care facility because a client was known to have or was suspected of having HIVIAIDS?

No

Question

Option

Skip

48. Receiving less care/attention than other clients

A. Never B. Once or twice

49. Extra precautions being taken in the sterilization of instruments used on

C. Several times D. Mostly

A. Never B. Once or twice

HIV-positive clients

C. Several times D. Mostly 
50.

Requiring some clients to be tested for HIV before scheduling surgery

51. Using latex gloves for performing noninvasive exams on clients suspected of having HIV

52. Because a client is HIV-positive, a senior health care provider assigned the client to junior health care providers

53. Testing a client for HIV without his/her consent

54. Health care providers gossiping about a client's HIV status

55. Is there anyone you know in the health care facility who is HIV-positive, but has not yet shown signs and symptoms of AIDS? How did you know that he/she has HIV infection?

\begin{tabular}{ll} 
No & Question \\
\hline 55.1 & The infected person told me her/himself \\
55.2 & Family member of infected person told me \\
$55.3 \quad$ Community member told me \\
$55.4 \quad$ I heard through general gossip/rumors \\
$55.5 \quad$ I heard from a health care provider where the person was tested \\
$55.6 \quad$ I read his/her health care institution record
\end{tabular}

A. Never B. Once or twice C. Several times D. Mostly A. Never B. Once or twice C. Several times D. Mostly

A. Never B. Once or twice C. Several times D. Mostly A. Never B. Once or twice C. Several times D. Mostly A. Never B. Once or twice C. Several times D. Mostly Option

A. Never B. Once or twice C. Several times D. Mostly A. Never B. Once or twice C. Several times D. Mostly A. Never B. Once or twice C. Several times D. Mostly A. Never B. Once or twice C. Several times D. Mostly A. Never B. Once or twice C. Several times D. Mostly

A. Never B. Once or twice

C. Several times D. Mostly

\section{Appendix II Operational definitions}

1. HIV case load: The number of HIV clients for whom the health care provider has given health care services during the last 6 months

- Low HIV case load: Fewer than ten HIV clients for whom the health care provider has given health care services during the last 6 months.

- High HIV case load: More than ten HIV clients for whom the health care provider has given health care services during the last 6 months. ${ }^{42}$

2. HIV knowledge

- Have in-depth HIV knowledge: Correct responses to at least two of the three HIV in-depth knowledge questions.

- No in-depth HIV knowledge: Correct response to less than two HIV in-depth knowledge questions.

- High basic HIV knowledge: Correctly identifying all body fluids that have high enough concentration of HIV to transmit the virus.

- Low basic HIV knowledge: Missing one or more body fluids that have high enough concentration of HIV to transmit the virus. ${ }^{15,30}$

3. Perceived institutional support was measured with three scales:

- The perception of supply-related institutional support had five items measured on three-point Likert scale, higher scores indicating higher perception of institutional support.

- The perception of policy-related institutional support had three items measured on three-point Likert scale, higher scores indicating higher perception of institutional support.

- The perception of protocol-related institutional support had seven items measured on three-point Likert scale, higher scores indicating higher perception of institutional support. 
Journal of Multidisciplinary Healthcare

Dovepress

\section{Publish your work in this journal}

The Journal of Multidisciplinary Healthcare is an international, peerreviewed open-access journal that aims to represent and publish research in healthcare areas delivered by practitioners of different disciplines. This includes studies and reviews conducted by multidisciplinary teams as well as research which evaluates the results or conduct of such teams or healthcare processes in general. The journal covers a wide range of areas and welcomes submission from practitioners at all levels, from all over the world. The manuscript management system is completely online and includes a very quick and fair peer-review system. Visit http://www.dovepress.com/testimonials.php to read real quotes from published authors.

Submit your manuscript here: http://www.dovepress.com/journal-of-multidisciplinary-healthcare-journal 